\title{
Fatal thrombotic event after infusion of recombinant activated factor VII after cardiac surgery
}

\author{
N. Pichon, MD, ${ }^{a, b}$ F. Bellec, MD, ${ }^{a}$ S. Sekkal, MD, ${ }^{c}$ J. P. Marsaud, MD, d,e M. Laskar, MD, PhD, ${ }^{c, e}$ B. François, MD, ${ }^{a, b}$ \\ and P. Vignon, MD, $\mathrm{PhD},{ }^{\mathrm{a}, \mathrm{b}, \mathrm{e}}$ Limoges, France
}

$\mathrm{H}$ emorrhagic shock is a major complication of cardiothoracic surgery that occurs when standard surgical and medical hemostatic procedures fail to stop hemorrhage. Recombinant activated factor VII (rFVIIa; NovoSeven, Novo Nordisk, Denmark) is a prohemostatic agent increasingly used as rescue therapy in cardiothoracic surgery, but its safety in this indication remains to be investigated. We report a fatal thrombotic event that occurred within 48 hours after the administration of rFVIIa for a refractory hemorrhagic shock after cardiothoracic surgery.

\section{Clinical Summary}

A 57-year-old hypertensive male patient underwent an aortic valve and ascending aorta replacement (Carbo-Seal Valsalva Ascending Aortic Prosthesis CP-023; CarboMedics, Austin, Texas) for a type A aortic dissection including both carotid arteries without antegrade carotid perfusion (Figure 1). Postoperatively, the patient had severe hemorrhagic shock resulting from active bleeding from the chest tubes $\left(10 \mathrm{~mL} \cdot \mathrm{kg}^{-1} \cdot \mathrm{h}^{-1}\right)$, despite the transfusion of $2700 \mathrm{~mL}$ of blood from a cell salvage machine, 9 units of packed red blood cells (PRBC), 12 units of fresh-frozen plasma (FFP), 2 units of pooled platelet concentrates, $2 \mathrm{~g}$ of fibrinogen, and calcium chloride. The patient had a metabolic acidosis $(\mathrm{pH} 7.24$, base-deficit $8.7 \mathrm{mEq}$ $\cdot \mathrm{L}^{-1}$, and lactates $9.11 \mathrm{mmol} \cdot \mathrm{L}^{-1}$ ), a coagulopathy (international normalized ratio (INR) 3.38 , platelet count $59 \times 10^{9} . \mathrm{L}^{-1}$, fibrinogen $0.79 \mathrm{~g} \cdot \mathrm{L}^{-1}$, activated partial thromboplastin time [APTT] $75.5 \mathrm{~s}$ ), and anemia $\left(71 \mathrm{~g} \cdot \mathrm{L}^{-1}\right)$. Owing to persistent bleeding exteriorized by chest tubes $\left(>500 \mathrm{~mL} \cdot \mathrm{h}^{-1}\right)$, the patient was again operated on at $\mathrm{H}+3$. A source of bleeding was disclosed and surgically repaired. Active bleeding through chest tubes persisted and led to a second surgical re-exploration under cardiopulmonary bypass, which failed to reveal any surgical source of bleeding. Refractory hemorrhagic shock (lactates $13.86 \mathrm{mmol} \cdot \mathrm{L}^{-1}$, hemoglobin $59 \mathrm{~g} \cdot \mathrm{L}^{-1}$ ) owing to sustained bleeding from chest tubes $\left(15 \mathrm{~mL} \cdot \mathrm{kg}^{-1} \cdot \mathrm{h}^{-1}\right)$ and severe coagulopathy (INR 1.74, platelet count $65 \times 10^{9} \cdot \mathrm{L}^{-1}$, APTT

From the Medical-Surgical Intensive Care Unit, ${ }^{a}$ the Centre de Recherche Clinique, ${ }^{\mathrm{b}}$ the Department of Thoracic and Cardiovascular Surgery, ${ }^{\mathrm{c}}$ and the Department of Anesthesiology, ${ }^{\mathrm{d}}$ Dupuytren Teaching Hospital, Limoges, France, and the University of Limoges, ${ }^{\mathrm{e}}$ Limoges, France.

Received for publication Aug 24, 2007; revisions received Sept 12, 2007; accepted for publication Oct 19, 2007.

Address for reprints: Nicolas Pichon, MD, Intensive Care Unit, CHU Dupuytren, 2 avenue Martin Luther King, 87042 Limognes, France (E-mail: nicolas.pichon@chu-limoges.fr).

J Thorac Cardiovasc Surg 2008;136:220-1

$0022-5223 / \$ 34.00$

Copyright $(\odot 2008$ by The American Association for Thoracic Surgery doi:10.1016/j.jtcvs.2007.10.084
45.9 s) persisted despite the continuous administration of more blood products (24 units of PRBC, 30 units of FFP, 5 units of pooled platelet concentrates, and $6 \mathrm{~g}$ of fibrinogen). The correct bilateral carotid perfusion was confirmed by transcranial Doppler monitoring during surgery. A transesophageal echocardiogram ruled out a cardiac source of emboli and excluded a compressive atrial hematoma. The administration of rFVIIa was discussed by cardiac surgeons, anesthesiologists, and intensivists. The empirical dosing scheme was an intravenous bolus injection of $8.4 \mathrm{mg}(\sim 90$ $\mu \mathrm{g} / \mathrm{kg}$ ) on the basis of published reports. After this single dose of rFVIIa, the bleeding from chest tubes decreased below $1 \mathrm{~mL}$. $\mathrm{kg}^{-1} \cdot \mathrm{h}^{-1}$ and the coagulopathy dramatically improved. No further second dose was administered. Our patient had no recurrence of bleeding and presented an adapted awakening without sedation within 24 hours. Unfortunately, 48 hours after the procoagulant injection, the patient exhibited a bilateral mydriasis with associated signs consistent with brain death. The computed tomographic cerebral scan confirmed an extended stroke resulting from a bilateral thrombosis of carotid arteries (Figure 2). The spouse declined the autopsy.

\section{Discussion}

Excessive postoperative bleeding is a common complication after cardiothoracic surgery with an incidence of $11 \% .^{1}$ Massive hemorrhage requiring surgical reinterventions occurs in about $6 \%$ of surgically treated patients. ${ }^{1,2} \mathrm{rFVIIa}$ is increasingly used with success to control refractory hemorrhage in patients undergoing complex cardiothoracic surgery. ${ }^{1}$ The estimated number of hospitalized patients treated with rFVIIa in the United States increased from 349 in 2000 (the first full year after licensure) to 4520 in $2004 .^{3}$ The single dose of rFVIIa administered to cardiothoracic surgical patients ranged from 11.1 to $180 \mu \mathrm{g} / \mathrm{kg}$ and $75 \%$ of adult patients received a total dose $90 \mu \mathrm{g} / \mathrm{kg}$ or less. ${ }^{1}$

There is no apparent thrombotic event after injection of rFVIIa in most reports and studies. ${ }^{1,4}$ Nevertheless, the safety of rFVIIa cannot be extrapolated from sporadic reports and accumulated experience remains limited. In a cumulated experience combining thromboembolic complications in patients who received rFVIIa for a refractory hemorrhage, an incidence of 5.3\% was reported and was similar to that reported from 13 Novo Nordisk-sponsored clinical trials regarding the use of rFVIIa in settings other than cardiac surgery. ${ }^{1}$ A word of caution emanating from the US Food and Drug Administration suggested an increase in thromboembolic events in patients treated with rFVIIa for unlabeled conditions. $^{3}$

It has been postulated that bleeding after cardiac surgery is frequently related to disseminated intravascular coagulation and that activating the hemostatic system with rFVIIa in this setting may increase the risk of thromboembolic events. ${ }^{5}$ Confounding factors to establish the relationship between rFVIIa administration and 

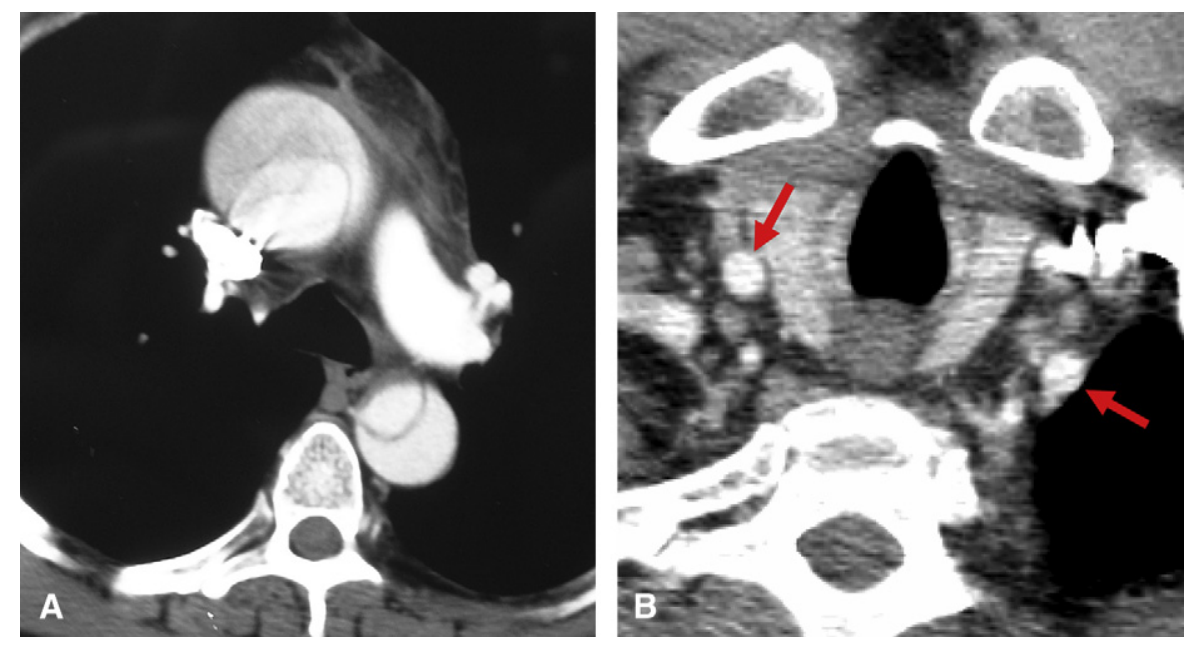

Figure 1. Transverse computed tomographic scan showing a type $A$ aortic dissection (A) with a bilateral carotid dissections (B: arrows).
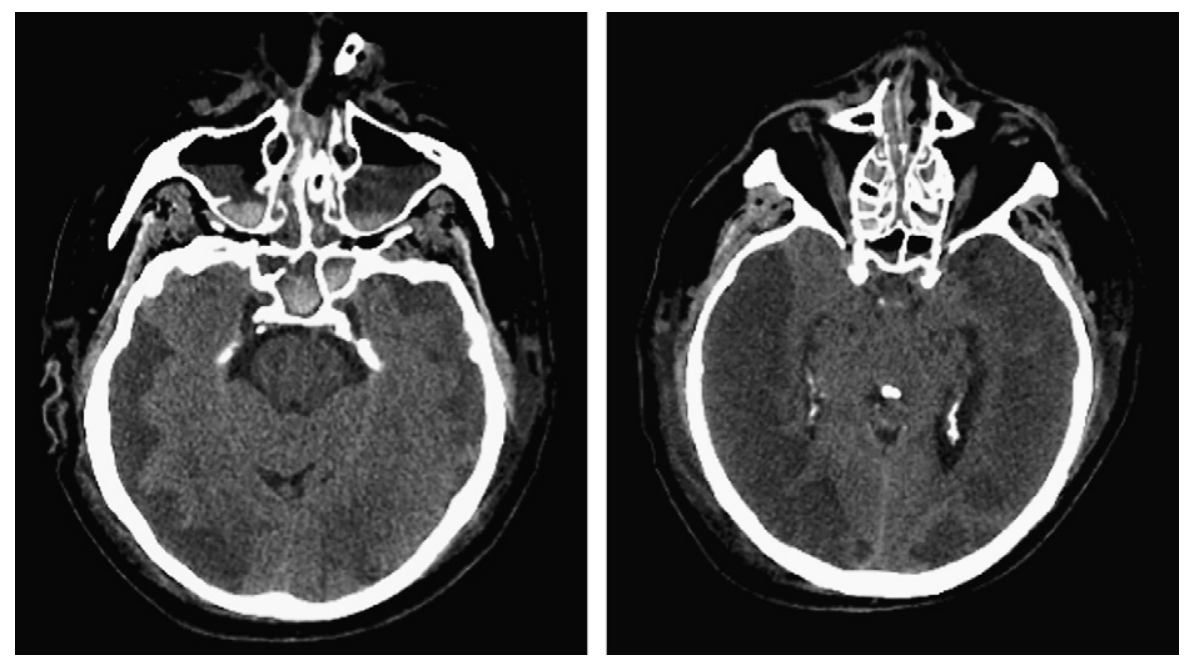

Figure 2. Bilateral ischemic stroke on CT cerebral scan.

reported thromboembolic events include up-regulation of tissue factor expression after cardiopulmonary bypass, which facilitates clot formation, concomitant medications, and pre-existing medical conditions. ${ }^{3,4}$ In our patient, the bilateral dissection of carotid arteries and the two cardiopulmonary bypass procedures were presumably major predisposing factors for stroke. Therefore, it seems difficult to assert that fatal stroke is only secondary to rFVIIa administration.

In conclusion, we report herein the first case of a bilateral thrombosis of carotid arteries leading to brain death after a single administration of rFVIIa in a patient who underwent complicated surgical repair of a type A aortic dissection extended to both carotid arteries. Although efficient as a rescue therapy in patients with hemorrhagic shock after cardiothoracic surgery, rFVIIa may be associated with an increased risk of stroke in this setting. Randomized controlled trials are needed to establish its safety.

\section{References}

1. Warren O, Mandal K, Hadjianastassiou V, Knowlton L, Panesar S, John K, et al. Recombinant activated factor VII in cardiac surgery: a systematic review. Ann Thorac Surg. 2007;83:707-14.

2. DiDomenico RJ, Massad MG, Kpodonu J, Navarro RA, Geha AS. Use of recombinant activated factor VII for bleeding following operations requiring cardiopulmonary bypass. Chest. 2005;127:1828-35.

3. O'Connell KA, Wood JJ, Wise RP, Lozier JN, Braun MM. Thromboembolic adverse events after use of recombinant human coagulation factor VIIa. JAMA. 2006;295:293-8.

4. Karkouti K, Beattie WS, Wijeysundera DN, Yau TM, McCluskey SA, Ghannam M, et al. Recombinant factor VIIa for intractable blood loss after cardiac surgery: a propensity scorematched case-control analysis. Transfusion. 2005;45:26-34.

5. VonHeymann C, Redlich U, Jain U, Kastrup M, Schroeder T, Sander M, et al. Recombinant activated factor VIIa for refractory bleeding after cardiac surgery: a retrospective analysis of safety and efficacy. Crit Care Med. 2005;33:2241-6. 